Article

\title{
Maximizing Green Infrastructure in a Philadelphia Neighborhood
}

\author{
Kate Zidar ${ }^{1}$, Timothy A. Bartrand ${ }^{2}$, Charles H. Loomis ${ }^{3}$, Chariss A. McAfee ${ }^{3}$, Juliet M. Geldi ${ }^{4}$, Gavin J. Riggall ${ }^{4}$, \\ and Franco Montalto ${ }^{1, *}$ \\ ${ }^{1}$ Department of Civil, Architectural and Environmental Engineering, Drexel University, Philadelphia, PA 19104, USA; \\ E-Mails: katezidar@gmail.com (K.Z.), fam26@drexel.edu (F.M.) \\ ${ }^{2}$ Corona Environmental Consulting, LLC, Rockland, MA 02370, USA; E-Mail: tbartrand@coronaenv.com \\ ${ }^{3}$ Charles Loomis Chariss McAfee Architects, 19103, Philadelphia, PA 19103, USA; E-Mails: CharlesL@LoomisMcafee.com \\ (C.H.L.), CharissM@LoomisMcafee.com (C.A.M.) \\ ${ }^{4}$ North Street Design, Philadelphia, PA 19130, USA; E-Mails: jgeldi@kssarchitects.com (J.M.G.), gavinriggall@gmail.com \\ (G.J.R)
}

* Corresponding author

Submitted: 13 May 2017 | Accepted: 26 September 2017 | Published: 31 October 2017

\begin{abstract}
While the Philadelphia Water Department (PWD) is counting on Green Stormwater Infrastructure (GI) as a key component of its long-term plan for reducing combined sewer overflows, many community stakeholders are also hoping that investment in greening can help meet other ancillary goals, collectively referred to as sustainable redevelopment. This study investigates the challenges associated with implementation of GI in Point Breeze, a residential neighborhood of South Philadelphia. The project team performed a detailed study of physical, social, legal, and economic conditions in the pilot neighborhood over the course of several years, culminating in the development of an agent-based model simulation of GI implementation. The model evaluates a) whether PWD's GI goals can be met in a timely manner, b) what kinds of assumptions regarding participation would be needed under different theoretical GI policies, and c) the extent to which GI could promote sustainable redevelopment. The model outcomes underscore the importance of private land in helping PWD achieve its GI goals in Point Breeze. Achieving a meaningful density of GI in the neighborhoods most in need of sustainable redevelopment may require new and creative strategies for $\mathrm{Gl}$ implementation tailored for the types of land present in those particular communities.
\end{abstract}

\section{Keywords}

agent-based modeling; green infrastructure; participatory modeling; stormwater; urban redevelopment

\section{Issue}

This article is part of the issue "Social Ecology of Sustainability", edited by Stephen Wheeler (University of California, Davis, USA), Christina Rosan (Temple University, USA) and Bjoern Hagen (Arizona State University, USA).

(C) 2017 by the authors; licensee Cogitatio (Lisbon, Portugal). This article is licensed under a Creative Commons Attribution 4.0 International License (CC BY).

\section{Introduction}

\subsection{City Context}

Philadelphia is a city of stark contrasts. On one hand, public safety, environmental quality, and property values in many of its residential neighborhoods are compromised by the presence of over 40,000 vacant proper- ties, responsible for $\$ 3.6$ billion in lost household wealth, \$20 million in City maintenance costs, and at least \$2 million in uncollected property taxes each year (Philadelphia Redevelopment Authority, 2010). Roughly one-third of the city's residents live in poverty (Romero, 2017). On the other hand, the City has emerged as a national leader in sustainable urban water management, as exemplified by the Philadelphia Water Department's (PWD's) Green 
Cities Clean Waters (GCCW) program, which pledges a broad and long-term investment in green infrastructure (GI) practices.

While the central goal for PWD is to use GI to reduce combined sewer overflows (CSOs), urban stakeholders are also hoping to see this investment provide jobs and job-training, reduce heat island effect, beautify neighborhoods, and raise property values (Travaline, Montalto, \& Hunold, 2015). Globally, Gl is increasingly discussed as an urban adaptation strategy, and particularly as a means of reducing flood and health risks due to both climate change and increasing extent and rate of urbanization, and associated environmental risks (Zhou, 2014). $\mathrm{Gl}$ is often viewed as a potential leveraging opportunity. Infrastructure investments mandated by the regulatory pressure to control CSOs are seen as an opportunity to also help revitalize residential communities, restore urban ecosystem function, adapt to changing climate conditions, and create green jobs, among other ancillary goals collectively referred to here as sustainable redevelopment.

However, as the GCCW program was structured at the time of this study, the likelihood that GI would be able to promote widespread sustainable redevelopment in many of the city's struggling residential neighborhoods appeared low. For one, cost factors limited the spatial extent of $\mathrm{Gl}$ that will be constructed in the public right-of-way. The City's goal was to use GI to manage the $2.54 \mathrm{~cm}$ (one inch) of runoff from $47 \%$ of the directly connected impervious areas within the city's combined sewer service areas, leading to the use of GI to treat runoff from 3,870 hectares $(9,564$ acres), citywide $^{1}$. However, given current and projected future average $\mathrm{Gl}$ costs in the public right-of-way $(>\$ 250,000 / \mathrm{GA}$ [green acre] and $\$ 120,000 / G A$, respectively), PWD appeared unable to self-fund all of the required GAs that needed to be installed across the City using streetscape GI (Christopher Crockett \& Marc Cammarata [PWD], personal communications, 2012).

Second, although a variety of carrots and sticks incentivized GI implementation on private property, these programs mostly targeted large and non-residential properties (Valderrama \& Davis 2015). PWD's innovative ParcelBased Billing and Stormwater Credits programs, for example, charges a stormwater fee to each non-residential parcel based its gross area and impervious area. Nonresidential property owners have the option to reduce or eliminate this charge by installing GI. PWD's current Stormwater Code specifies that all earth disturbances in excess of $1,394 \mathrm{~m}^{2}\left(15,000 \mathrm{ft}^{2}\right)$ manage the first 2.54 $\mathrm{cm}$ of runoff, effectively incentivizing $\mathrm{Gl}$ implementation for large redevelopment projects (PWD, 2014). This requirement, however, will not lead to incorporation of GI into the redevelopment situated on the more common, smaller lots that predominate in Philly's residential neighborhoods. The presence of privately owned vacant land is particularly important to prospects of GI (Mon- talto et al., 2012; Travaline et al., 2015), and this factor is ever evolving over time due to redevelopment. As sites are developed, GI opportunities may be lost.

\subsection{Neighborhood Context}

Starting in 2009, the project team began investigating the challenges associated with implementation of $\mathrm{Gl}$ in Point Breeze (population 23,585), a $1.75 \mathrm{~km}^{2}$ residential neighborhood of South Philadelphia (see Figure 1).

Given its proximity to Philadelphia's Center City, Point Breeze faces intense redevelopment pressure, and concerns about gentrification are common among the long-term residents. Most of the area was originally developed during the second half of the nineteenth century, and the neighborhood has historically been comprised of middle class and working class families. Like many other older sections of Philadelphia, Point Breeze experienced decline after World War II due to a waning manufacturing sector, overall population loss, and aging infrastructure. In 2000, roughly one-third of households were below the poverty line. More than $80 \%$ of the population is African-American.

Since 2000, community development experts have observed the onset of gentrification trends in Point Breeze, signaled by the scale, speed, and price point of new construction and the target audience of new businesses. Income levels and property values have grown most notably in the northern portion of the neighborhood, where demographic data reveals increases in white residents and residents with college degrees (Philadelphia Research Initiative, 2016).

Meanwhile, long-term residents of Point Breeze experience ongoing barriers to living wage employment such as limited educational attainment and criminal records. Accordingly, traditional workforce development training programs are of little help to many, and local stakeholders have expressed the need to develop a trained urban "green collar" workforce to meet the present and future employment demands of the steadily emerging environmental business sector (Conrad, 2009).

The extent to which residents experience ancillary benefits or improvements in neighborhood livability from the GCCW program is assumed to be directly proportional to the density of $\mathrm{GI}$ facilities that are installed. Achieving a meaningful density of GI in Philadelphia's struggling residential neighborhoods thus requires the development of new and creative strategies for fostering Gl implementation on the types of land present in these particular communities, through alternative financing mechanisms and the forging of new forms of relationships between the City, the community and the private sector.

\section{Project Goals and Methods}

The general study goal was to investigate how GI programs in Philadelphia can be customized to take max-

\footnotetext{
${ }^{1}$ PWD defines the term "greened acre" (GA) as a region of $4,047 \mathrm{~m}^{2}$ (1 acre) over which $2.54 \mathrm{~cm}$ (one inch) of runoff have been treated with GI.
} 


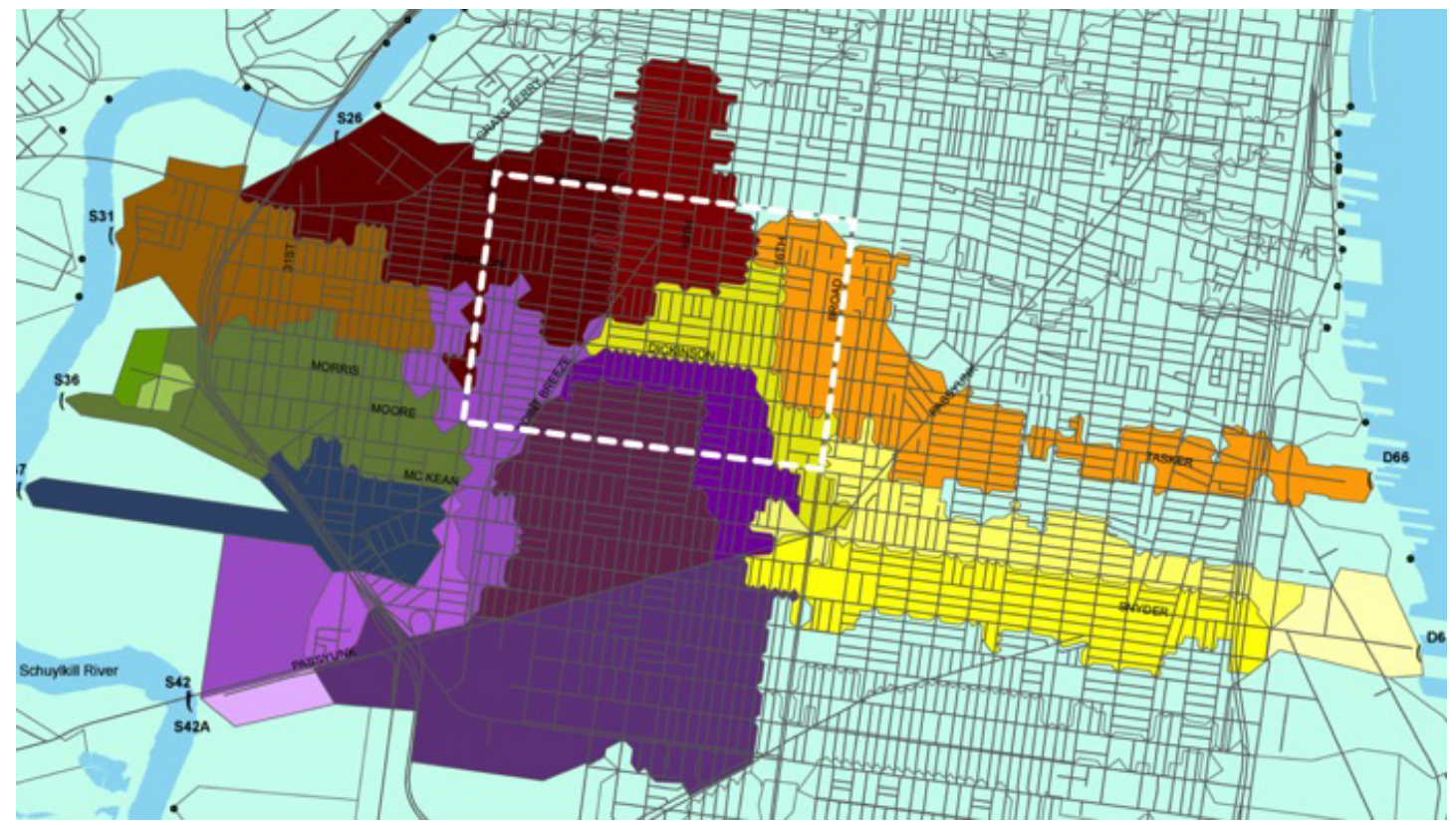

Figure 1. The Point Breeze neighborhood, with CSO drainage areas.

imum advantage of the opportunities presented by individual neighborhoods and their residents, thus promoting sustainable redevelopment. Focusing on Point Breeze, the team performed a detailed study of physical, social, legal, and economic conditions over the course of several years. This process included a physical site analysis, summarizing key features of development and planning in Point Breeze, an outreach effort to identify and summarize key features of $\mathrm{GI}$ technologies and programs that could be implemented, a legal study investigating issues associated with moving stormwater across property lines, and the creation of a database tracking GI cost, performance, and site applicability factors derived specifically for Point Breeze. The results of these various analyses are reported in detail in Travaline et al. (2015). In this study, we utilize these empirical results to develop an agent-based simulation of GI build out in Point Breeze. This simulation is used to evaluate the extent to which GI offers an opportunity for sustainable redevelopment.

\subsection{Agent-Based Models for Green Infrastructure}

A preliminary version of the Point Breeze agent-based model ( $A B M$ ) was described in an earlier paper (Montalto et al., 2012), with an adapted and enhanced description of the model provided below. ABMs offer an accessible way for decision makers to assess the sustainability of complex infrastructure decisions by simulating their underlying physical and social factors (Jager \& Mosler, 2007). An ABM allows physical and social/cultural environments to be modeled concurrently (Berger, Birner, McCarthy, Díaz, \& Wittmer, 2007), and elucidates complex interactions between subsystems (Bah, Touré, Le Page, Ickowicz, \& Diop, 2006). Autonomous agents are crafted within an ABM to adhere to a set of behavioral "rules". Agents may "learn" based on changes within the system, or their be- havior may remain fixed. The agents interact with one another as well as their environment, patterns emerge, and the system itself evolves. In this way, ABMs are used to explore the roles that dynamic processes play in shaping the "emergence" of a particular outcome.

Although ABMs are useful as a predictive tool, their unique value is to explore relationships between heterogeneous agents and agent classes (Grimm et al. 2010). ABMs can be used to test whether a theory will produce its expected result, such as how a policy proposal might change behavior within a population. In this way, ABMs are a powerful tool for developing simulations that incorporate social science theories into representations of physical systems (Moss \& Norling, 2006), and supporting decision-making by rapidly testing alternate solutions to a given problem (Voinov \& Bousquet, 2010). Although many water-related $A B M$ studies are described in the literature (Barthel, Rojanschi, Wolf, \& Braun, 2005; Berger et al., 2007, Davis, 2000; Fagiolo, Moneta, \& Windrum, 2007; Tillman, Larsen, Pahl-Wostl, \& Gujer, 2005), efforts to apply this modeling approach to GI are fairly new.

As described in Montalto et al. (2012), the Point Breeze ABM has been used to explore the spatiotemporal emergence of rain gardens and green roofs in Point Breeze under scenarios involving economic self-interest, physical compatibility of GI with lot characteristics, and additional insights into the possible behavior of property owners. In this article, a revised and enhanced version of the model is used to compare different GI implementation strategies in terms of a) whether PWD's GA goals could be met in a timely manner in Point Breeze, b) what kinds of assumptions regarding participation and adoption would be necessary to achieve the GI implementation achieved as a result of different theoretical GI policies, and c) the extent to which GI could promote sustainable redevelopment in Point Breeze. 


\subsection{Model Overview}

The ABM was programmed in Netlogo. In the model, implementation of $\mathrm{Gl}$ by public agencies and private landowners in Point Breeze is simulated over a 30-year project timeframe. At each quarterly time step, public agencies and owners of single family residences decide whether to adopt Gl options that are physically feasible on their properties and within their budget. On any given time step, GI adoption is physically constrained to those tax lots and public spaces with sufficient area to house the $\mathrm{GI}$, and where synergistic activities such as roof replacement or street milling/reconstruction are currently occurring. The model steps through 30 years of simulation, updating the inventory of GI projects and the perception of PWD and private land owners at the end of each quarterly time step.

Because an overarching goal of the modeling effort was to evaluate the importance of interacting spatial, temporal, social/institutional, and economic dynamics, we elected to not simulate any of the hydrologic or hydraulic phenomena typically included in municipal GI modeling efforts. Instead, we assume that all instances of GI implemented in the simulation are sized to be able to store a volume of stormwater equivalent to $2.54 \mathrm{~cm}$, the capture standard at the time of the research, multiplied by the area of their assumed catchment areas. However, using typical GI design standards as a guide, we have established limits on the size of individual GI systems, and constraints on their placement. For example, the total depth of excavation for stormwater bump-outs is limited to 1.5 $\mathrm{m}$, to minimize labor-related compliance activities during construction. Setbacks of $1.5 \mathrm{~m}$ from building foundations are assumed for all private property GI. Depressions are limited to $0.3 \mathrm{~m}$ to avoid the creation of trip hazards.

The aggregate neighborhood percentages are presented in a time series chart. Although the ABM can theoretically be programmed to output a wide range of model metrics, for this study, we have elected to present two different types of outputs. First, we present the percent of each block greened at the end of the 30-year simulation period (i.e., the percent of directly-connected impervious area on each block over which the first $2.54 \mathrm{~cm}$ of runoff is controlled for each year of the 30-year simulation). The aggregate neighborhood percentages are presented in a time series chart. Then, we show the net greened acreage associated with each type of Gl implemented in each simulation.

\section{Model Development}

Three different GI program scenarios were modeled. The model runs relate to three different types of GI implementation, per PWD's December 2011 Adaptive Management Plan. These include: a) PWD-initiated GI, b) GI linked to public infrastructure projects, and c) private GI. The differences between the three different model scenarios are determined by whether or not the features summarized in Table 1 are turned "on" or "off". In the model, all scenarios are cost equivalent and constrained by available funds.

\subsection{Selection of Agents}

The process used to select particular classes of agents to include in the model, and to assign individual attributes and behavioral rules to them involved a variety of widely recognized (Smajgl, Brown, Valbuena, \& Huigen, 2011) empirical methods such as surveys, interviews, seeking expert knowledge, and participant observation. The results of these efforts are summarized in Travaline et al. (2015). This outreach effort suggested local perceptions if GI were many and varied, and future interaction between PWD and the community will likely change them further. In the ABM, such preferences can be dynamically adjusted. For example, the GI cost-sharing relationships

Table 1. Features alternatively toggled "on" of "off" in the model runs.

\begin{tabular}{|c|c|}
\hline Feature & Description \\
\hline $\begin{array}{l}\text { Use of publicly owned, corner, vacant lots for } \\
\text { infiltrating runoff generated within the census block. }\end{array}$ & $\begin{array}{l}\text { This is an extension of PWD-initiated GI program that essentially } \\
\text { would allow PWD to treat runoff originating on private property, } \\
\text { but that relies on back alleys for conveyance. }\end{array}$ \\
\hline $\begin{array}{l}\text { Use of interior, and corner, vacant lots owned and } \\
\text { managed by a private GI Banking and Credit } \\
\text { Program for infiltrating runoff generated within the } \\
\text { census block. }\end{array}$ & $\begin{array}{l}\text { This is a scenario wherein a private third party is allowed to } \\
\text { purchase and use privately owned vacant land for managing } \\
\text { stormwater, also relying on back alleys for conveyance. }\end{array}$ \\
\hline $\begin{array}{l}\text { Implementation of a Raincheck program, whereby } \\
\text { the cost of private GI (e.g. rain gardens and green } \\
\text { roofs) is subsidized by } 80 \% \text { by PWD. }\end{array}$ & This is an additional incentive for GI on private property. \\
\hline $\begin{array}{l}\text { Implementation of a Community-Assisted } \\
\text { Maintenance Program for engaging the local } \\
\text { community in operation and maintenance (O\&M) } \\
\text { for nearby GI. }\end{array}$ & $\begin{array}{l}\text { This program is indirectly associated with private } \mathrm{Gl} \text { adoption, } \\
\text { since the assumption is made that by engaging the local } \\
\text { community in the } \mathrm{O} \& \mathrm{M} \text { of } \mathrm{Gl} \text {, they will develop a more favorable } \\
\text { opinion of } \mathrm{Gl} \text { and be more likely to adopt themselves. }\end{array}$ \\
\hline
\end{tabular}


that evolve between PWD and other city agencies can be changed in time, as can private property owner GI adoption rates, in response to the shifts in public opinion that could occur as $\mathrm{Gl}$ becomes a more common.

Following the framework and nomenclature introduced by Smajgl et al. (2011), agent-classes were identified principally from expert knowledge, the interviews, and participant observation. Agent attributes were devised based on surveys, census data and geospatial information collected by the project team.

Three principle agents are included in the model: the water utility (PWD), local community organizations, and property owners. The rules governing PWD's actions were derived from PWD's Implementation and Adaptive Management Plan with some modifications as described below. Property owner and community organization agents were assigned to the appropriate agent type using geospatial and downscaled census data. Disproportionate up-scaling using Monte Carlo approaches were used to initialize attributes of the entire population of these agents from the samples associated with the empirical work.

Initial conditions with respect to the age of a property owner's roof, property owner income, property values, tenure status (renter v. owner-occupied), and community organization membership for all tax lots were generated randomly at the outset of each simulation from the map data and community-derived data. It is assumed that there was no extant $\mathrm{Gl}$ in the study neighborhood at the beginning of the simulation. However, we count un- developed green space as among the GA present in the neighborhood, meaning that conversion of vacant lots to buildings is a loss of $G A$.

Owner occupancy and mean household income were assigned for each property based on random values drawn from the distribution of owner/renter occupancy status and income values reported for the respective census block group. Each property located within one of the geographic districts of interest to the community organizations was also assigned a probability of membership based on the number of members purported by the organization, divided by the number of properties in the area of interest. As an initial condition, each property was also assigned a residual useful roof life drawn from a uniform distribution with a minimum of 0 months and a maximum of 360 months. This residual roof life is reduced as time progresses in the model.

The initial conditions of the model were verified and calibrated by comparing histograms and descriptive statistics (minimum, maximum, mean and standard deviation) of specific parameters generated by the model (household income, roof age, proportion of properties rented per block) with actual GIS and spatially explicit census data.

\subsection{Scheduling of Agent Decisions and Actions}

Different agent decisions and actions take place at quarterly and yearly intervals. A summary of agent decisions and actions is presented in Table 2.

Table 2. Schedule of recurring events in the Point Breeze ABM.

\section{Occurrence Events in ABM}

Annual PWD learns about exogenously scheduled public infrastructure projects such as street projects, school projects, and park projects that can include a GI component.

PWD updates its list of upcoming self-initiated GI projects.

PWD establishes an annual budget for GI construction and O\&M based on the number of GA implemented to date.

PWD increases water and sewer rates at $6.5 \%$ per year.

Annually, the GI Banking and Credit Program (BCP) sells its credits to PWD customers from outside of Point Breeze who elect to purchase GI credits in lieu of onsite stormwater management, at a profit.

Quarterly If Raincheck program has been implemented, PWD acquires knowledge about funded requests for Raincheck program over the previous year.

If publicly owned corner vacant properties are being used for stormwater management, PWD identifies all projects it can afford during this quarter.

If Raincheck program has been implemented, PWD acquires knowledge about funded requests for Raincheck program over the previous year.

PWD makes GI offers. Collaborating agents respond. GI is implemented. Construction costs are deducted from that year's annual budget.

PWD updates its database of GI instances and recalculates the \% green for each street block and for the neighborhood at large

Loop back to 1 until the end of the year, then go back to the next annual calculation 
Generally speaking, PWD evaluates its outstanding GA goals for the neighborhood (in the model PWD is continually attempting to manage the first $2.54 \mathrm{~cm}$ of runoff over $47 \%$ of the directly-connected impervious area in Point Breeze), and its remaining annual budget on an annual basis. On quarterly intervals, it generates lists of planned earth disturbances that could be leveraged for $\mathrm{Gl}$ construction and determines whether the residual amount of its annual GI budget has been depleted. Based on what is left, PWD may make offers to public and private partners, who then decide whether or not to adopt additional Gl. The general sequence of PWD decision-making is graphically depicted in Figure 2 .

For projects conducted on public property such as sidewalks and parks, the contribution required of public agencies to construct and maintain $\mathrm{Gl}$ is the difference between the actual cost (unit cost * size of GI) and the PWD leverage (PWD contribution * size of GI). If the PWD offer exceeds the construction costs, PWD is assumed to pay the entire construction cost and the public partner is assumed to pay nothing.

Cost per GA is assumed to decrease somewhat in time as a result of the economic learning curve. See Figure 3 for a graphic representation of this cost calculation.

\subsection{Gl Sizing Assumptions}

A range of assumptions was made in order to size each anticipated Gl type for inclusion in the model. Streetscape Gl accommodates runoff from the street,

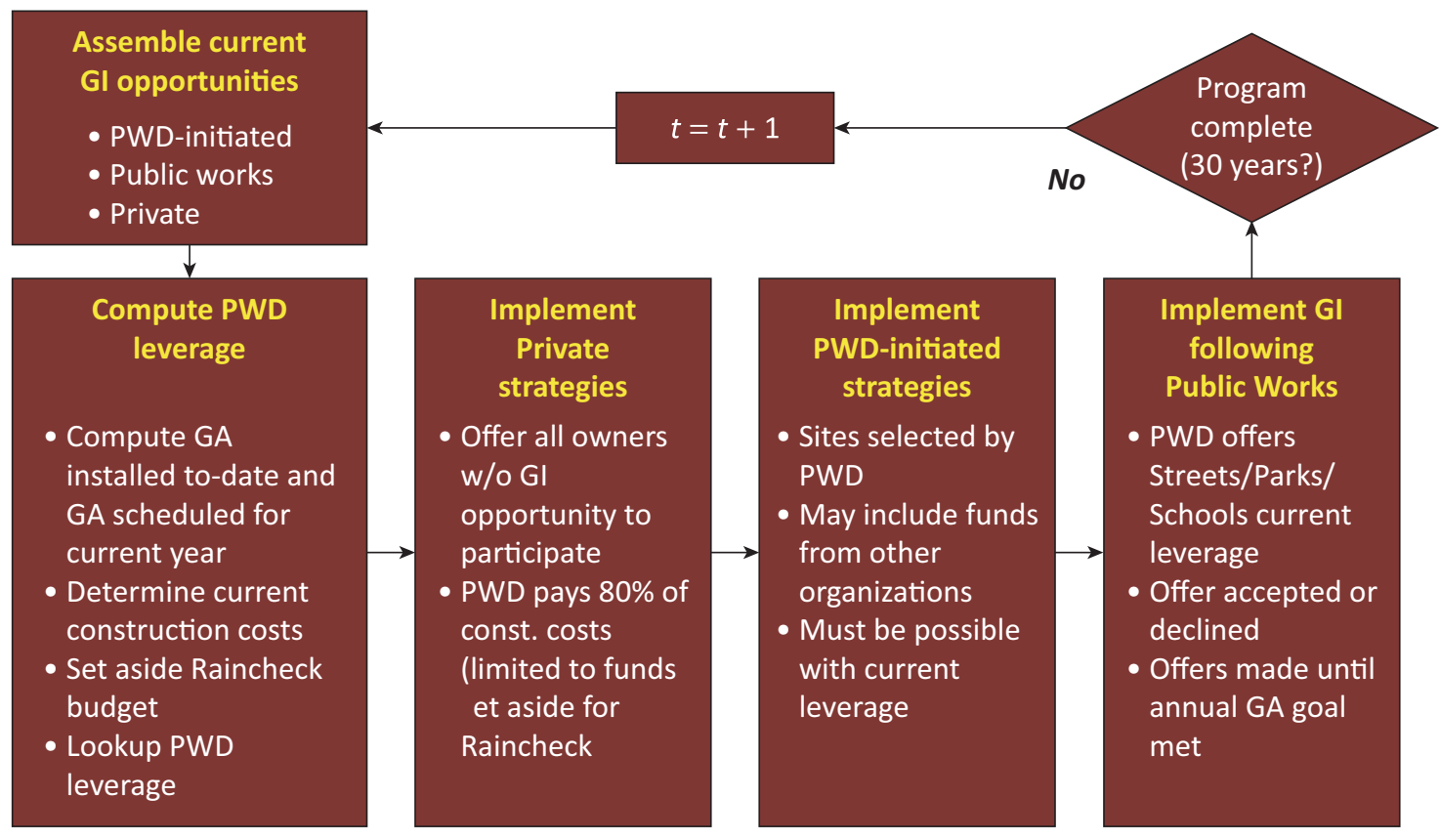

Figure 2. Flowchart depicting PWD's decision-making model.
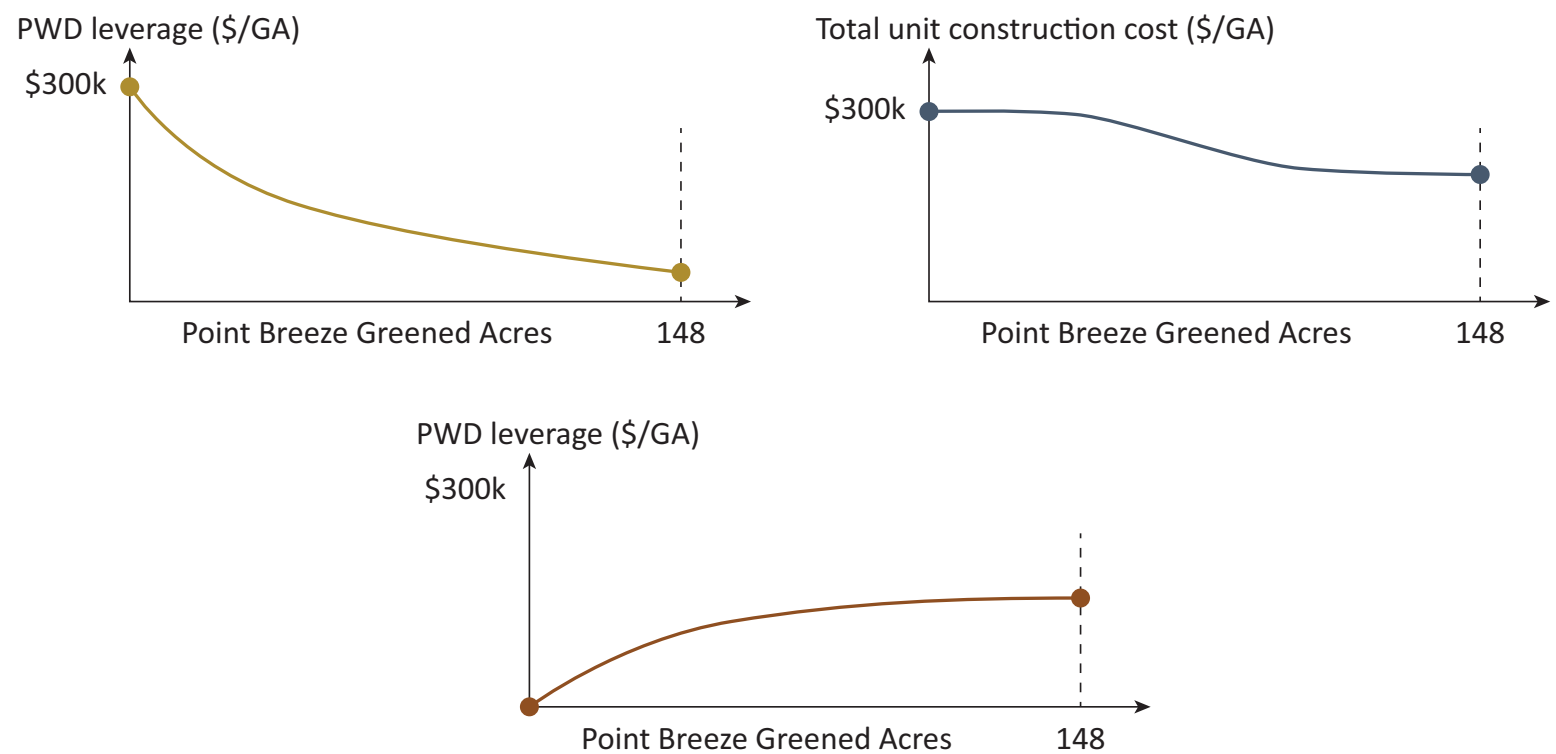

Figure 3. Calculation of PWD's leverage amount. 
the sidewalks and any downspouts routed to the fronts of houses. Streetscape GI comprised of a combination of stormwater bump-outs, parking lanes with pervious pavement, and stormwater tree trenches.

The stormwater bump-out design is based on traffic and parking requirements, and its dimensions and stormwater storage capacity are fixed. One bump out is built per street segment, assuming flow is only in one direction for a given street segment. If the bump out does not have sufficient capacity to accommodate one half of the street's runoff, pervious paving is added to the parking lane to make up the difference. Pervious pavement is built in the parking lane only and can be built to the ends of the road segment, although from a cost perspective, the spatial extent of pervious paving should be kept to a minimum to reduce excavation and disposal costs.

Stormwater tree trenches are built to accommodate the runoff generated on the side of the street opposite the bump out. We assume that, given the relatively narrow streets in Point Breeze, bump-outs on both sides of the street are rarely feasible due to space limitations. Stormwater tree trenches are constructed with a minimum $\sim 4 \mathrm{~m}$ setback from street segment ends. This results in engineered tree pit lengths typically in increments of about $8 \mathrm{~m}$. The trenches themselves are assumed to be about $1 \mathrm{~m}$ wide so as not to impede sidewalk traffic, and are not set back from the curb, since parking is assumed on the bump-out side of the street only.

A variety of $\mathrm{Gl}$ options occur on private property in the model. These can be generally classified as rain gardens and green roofs. In some cases, the rain gardens are placed on vacant parcels and runoff from roofs within the census block is routed there through back alleys.

In the model, PWD offers private property owners a one-time $\$ 100$ credit towards their water bill to install a rain garden. In contrast to the green roof program (described below) which kicks in when owners undertake regular roof maintenance, PWD would cover the entire life cycle cost of the rain gardens and offer the $\$ 100$ credit because there is otherwise no motivation for individuals to make any such modifications to their backyards. The monetary incentive was inspired by the successful Portland, OR downspout disconnection program, which offered a similar one-time financial incentive to property owners who agreed to divert their downspouts from conventional drainage systems.

Rain gardens are assumed to be located on private developed lots and on vacant lots, given a variety of different GI policies considered in the model. We assume that the area of a rain garden is the tax lot area $\times \sim 2.5 \mathrm{~cm}$ divided by $\sim 5 \mathrm{~cm}$ (corresponding to a $\sim 5 \mathrm{~cm}$ depression, or almost $1 \mathrm{~m}$ of engineered soil with $30 \%$ porosity), and minimum required setback of rain garden from buildings is $\sim 1.5 \mathrm{~m}$.

Green roofs are considered viable GI options for properties whose roof area is at least $28 \mathrm{~m}^{2}$, under the assumption that the benefit to the homeowner and to PWD for building a green roof does not justify the cost when the green roof does not capture a significant fraction of the lot runoff. Because there are very few pitched roofs in the study neighborhood, all roofs meeting the size limit are considered viable for green roofs. This assumption does not consider the condition of the house and its ability to support a green roof and may result in some overestimation of the number of properties eligible for a green roof. Owners have the option of adopting green roofs only at such time that the roof is being replaced. Green roofs are implemented through a cost-sharing strategy, based on the incentive program described in Montalto et al. (2007). When the useful life of an existing roof is expired, willing property owners would pay the price of a new conventional roof, but would actually get a green roof, and a commitment from PWD to maintain it as a stormwater management facility for its entire useful life.

\subsection{Factors Influencing Gl Adoption on Behalf of Private Property Owners}

In the model, adoption of GI by private property owners is determined by a variety of factors. Generally speaking, we assume that property owners are influenced by their own experiences with $\mathrm{Gl}$, as well as the experiences of members of their social network. We assume that they consider the functionality, aesthetics, and impact of the $\mathrm{GI}$ technologies that they encounter in their community.

\subsubsection{GI Encounters}

Private property owners develop preferences and perceptions about GI based on the GI they encounter directly and indirectly. Directly encountered GI includes $\mathrm{GI}$ on the landowner's property, GI on the landowner's block, Gl on nearby parks or schools, GI on the landowner's associates' property on neighboring blocks, and GI on transportation corridors and commercial corridors the landowner uses. Indirectly encountered GI includes $\mathrm{Gl}$ constructed and maintained by associates belonging to groups within their social network.

Landowners value directly- and indirectly-encountered GI differently. Directly encountered GI is assessed based on its functionality, its aesthetics and its impact. In the absence of other information, we assume that neighborhood residents value all directly encountered GI using the same criteria. That is, the importance an individual places on functionality, aesthetics and impact is the same for each directly encountered GI installation.

\subsubsection{A History of GI Encounters and Their Impacts}

The functionality, aesthetics and impact of each GI installation in Point Breeze are tracked during the ABM simulation of PWD's stormwater program. Each of the features is stored as an index with a value between 0 (no benefit) to 1 (fully providing benefit). An individual's "history" 
with directly-encountered $\mathrm{Gl}$ is calculated and tracked as:

$$
\Gamma_{\text {hist }}=\frac{1}{N_{\text {direct }}} \sum_{j=1}^{N_{\text {direct }}} \frac{1}{3}\left(\gamma_{f, j}+\gamma_{a, j}+\gamma_{i, j}\right)
$$

where $\Gamma_{\text {hist }}$ is the historical experience a landowner has with $\mathrm{Gl}$ (number between 0 and 1), $\mathrm{N}_{\text {direct }}$ is the number of $\mathrm{Gl}$ implementations the landowner has direct experience with, and $\gamma_{f}, \gamma_{a}$ and $\gamma_{i}$ are the GI functionality, aesthetics and impact indices, respectively. These factors are based on the research team's interaction with the community. Because Gl perception is the cumulative experience of Point Breeze residents, the historical experience at a given time step is set equal to the twoyear (eight-quarter) moving average $\Gamma_{\text {hist }}$ for each tax lot owner, i.e.,

$$
\Gamma_{\text {hist }}^{q}=\frac{1}{8} \sum_{k=0}^{7} \Gamma_{\text {hist }}^{q-k}
$$

where $q$ denotes the current quarter (present time).

The functionality of a given GI implementation is dependent upon its upkeep through O\&M, as well as random acts of nature or other damage that reduce GI functionality. Although all private GI owners are likely to maintain their GI (since they chose to adopt it in the first place), it is not a certainty. By contrast, it is assumed that GI on public property, commercial establishments and lands maintained by a stormwater management $\mathrm{BCP}$ always receive required $\mathrm{O} \& \mathrm{M}$ and function properly. The likelihood that a private landowner maintains $\mathrm{Gl}$ is dependent on the owner's experience with GI. Owners more positively disposed toward GI (as measured by the owner's instantaneous $\Gamma_{\text {hist }}$ value) are more likely to maintain the GI over which they have control. In this way the GI functionality index for a given GI implementation is represented as:

$$
\gamma_{f}=0.5+0.5 \times \Gamma_{\text {hist }}^{q-1}
$$

where $\Gamma_{\text {hist }}^{q-1}$ is the historical experience with GI for the GI owner on the previous quarter for $\mathrm{GI}$ on private property and is equal to 1 for $\mathrm{GI}$ on public lands or lands owned by the BCP.
Gl aesthetics are derived from their design, and are obviously subjective. For this study, GI systems that are specifically designed for public spaces or specifically to enhance residents' experiences (e.g., GI that preserves open or green space) are assigned a positive aesthetic value whereas $\mathrm{Gl}$ designed purely for functionality (e.g., porous pavement) is assumed to have limited aesthetic value. Values assigned to the different sorts of GI considered for Point Breeze (and several not currently in consideration) are provided in Table 3, and are assumed to be static during the simulation. The authors acknowledge that in actually aesthetic value will vary from person to person and potentially also change in time, and that the values in Table 3 represent a simplification. Future work will seek to better quantify the dynamic and heterogeneous aesthetic impact of GI in Point Breeze.

The impact a Gl implementation has on its owner may be environmental, financial, or social. As with aesthetics, the Gl impact is a feature of the Gl type and assumed invariant over time in this simplified modeling effort. GI impact indices, based on the research team's interaction with this community and others, are listed in Table 4. For each GI type a brief description of the primary impacts anticipated are listed.

\subsubsection{GI Adoption Algorithm}

Owners of single-family residences differ in their likelihood of adopting GI based on the following attributes: residence status (are they resident owners or landlords?), residence status of their neighbors, household income, their experience with $\mathrm{Gl}$, exposure to $\mathrm{Gl}$ in the vicinity of their residence, and the physical constraints of their property.

Each of these factors was included for predicting the likelihood of single-family residence GI adoption. The model predicts the probability that, on a single time step and with a known incentive from PWD (which may be $\$ 0$ or more), the owner of a single-family residence elects to build a rain garden or green roof. The probability of adoptions is represented by:

$$
P_{\mathrm{Gl} \text { adoption }}=f_{s} \times f_{w} \times f_{e} \times \Gamma_{\text {hist }} f_{k}
$$

Table 3. Aesthetic indices assigned to Point Breeze GI types.

\begin{tabular}{lc}
\hline Gl type & Aesthetic index \\
\hline Transportation corridor GI (high visual impact) & 1.00 \\
Demonstration projects (e.g., basketball court) & 1.00 \\
School and Park GI & 0.75 \\
Green roofs & 0.75 \\
Vacant lot stormwater BCP GI & 0.75 \\
Curb bump-outs (penalized because some drivers may resent them) & 0.50 \\
Engineered tree pits with trees & 0.50 \\
Engineered tree pits without trees & 0.25 \\
Backyard rain gardens & 0.25 \\
Porous pavement & 0.25
\end{tabular}


Table 4. GI Impact indices for GI in the Point Breeze ABM.

\begin{tabular}{lll}
\hline GI type & Impact index & Primary impacts \\
\hline Transportation corridor GI (high visual impact) & 0.50 & Educational \\
Demonstration projects (e.g., basketball court) & 1.00 & Social, environmental \\
School and Park GI & 1.00 & Social, environmental \\
Green roofs & 0.50 & Environmental, health \\
Vacant lot stormwater BCP GI & 1.00 & Social, environmental, economic \\
Curb bump-outs & 0.50 & Environmental \\
Engineered tree pits with trees & 0.50 & Environmental, economic, health \\
Engineered tree pits without trees & 0.25 & Environmental \\
Backyard rain gardens & 0.25 & Environmental, economic \\
Porous pavement & 0.25 & Environmental \\
\hline
\end{tabular}

where $f_{s}$ is a spatial feasibility factor ( 1 if the property can accommodate the rain garden or green roof, 0 otherwise), $f_{w}$ is a willingness factor, set such that each owner has a 0.2 probability of adoption GI over the 30 year ( 120 quarter) simulation, $f_{e}$ is an economic factor (described below), $\Gamma_{\text {hist }}$ is the property owner's GI history (described above) and $f_{k}$ is a knowledge factor (described below).

The economic factor assumes that adoption is more likely if the benefit received from implementation is significant in comparison with household income. The economic factor is implemented as a logistic function dependent on a factor, $f_{e}$, which is based on household income. At the outset of the simulation each property with land use of "single family" is randomly assigned an income based on the US Census average and standard deviation income for the census block in which the tax lot resides. The logistic function was scaled such that it varies between 0.5 and 0.9 over the range of incomes in Point Breeze:

$$
f_{e}=\frac{1}{1+e^{-(\gamma-0.1) / 0.152}} ; \quad \gamma=\frac{l_{\text {PWD }}}{\text { Income }}
$$

where $I_{\text {PWD }}$ is the incentive offered by PWD (Model 3 only) and "Income" is the monthly household income.

The knowledge factor takes into account the owner's residency status, surroundings and associations and is calculated as:

$$
\begin{gathered}
f_{k}=\frac{1}{1+e^{-\left(x_{\text {lot }}-2.944\right) / 0.849}} ; \\
x_{\text {lot }}=1-r_{\text {lot }}+2 m_{\text {owner }}+\left(\frac{n_{\mathrm{Gl}}}{n_{p}}\right)_{\text {block }}+\left(\frac{n_{r o}}{n_{p}}\right)_{\text {block }}
\end{gathered}
$$

where $r_{\text {lot }}$ is 0 if the property is a rental property and 1 if the lot is owner-occupied, $m_{\text {owner }}$ is the number of group memberships of the lot owner, $n_{\mathrm{GI}} / n_{p}$ is the fraction of properties on the tax lot's street block with GI and $n_{r o} / n_{p}$ is the fraction of properties on the tax lot's street block that are resident-owned. The knowledge function was scaled to provide a probability between 0.03 and 0.97 over the range of values expected for $x_{\text {lot }}$ in the Point Breeze neighborhood.

\section{Description of Model Runs}

\subsection{Model 1-Baseline Scenario}

This scenario was developed to reflect PWD's most current strategy for GI implementation, as generally represented in the PWD's Implementation and Adaptive Management Plan. In this scenario, PWD funds only GI projects on streets and other public lands, like parks and schools, in coordination with other public agencies. GI on publicly owned vacant parcels and GI on private property are not funded, though private single-family residences may choose voluntarily to implement Gl if they have sufficient space. PWD tracks the evolution of GI on private properties, and takes credit for it.

To spatially illustrate some of the GI considered in this study, and more fully flesh out the scenarios generated in the model runs, conceptual design drawings were developed visualize the $\mathrm{Gl}$ that could be generated given the model assumptions and the scenario results. Conceptual designs corresponding to Model 1 (see Figures 4 and 5) target public surface run-off managed on public property with streetscape GI, the array of stormwater bump-outs, pervious paving, and tree trenches already introduced.

Stormwater bump-outs and pervious paving are located on the parking side of the street, with stormwater tree trenches in the sidewalk along the travel side. All of the street scale Gl overflows into the combined sewer. In Model $1, \mathrm{Gl}$ could be used as a physical planning tool to establish 'gateways' to residential blocks, improve conditions for pedestrians by minimizing cross-walk distances, and limiting disruption to parking spaces and the interior of the block by targeting work to the first $21.3 \mathrm{~m}$ of the residential street.

Through the interior of the block, pervious pavement is used in the parking lane. Paving materials could be distinguished using a clearly defined separator or by using permeable pavement in a contrasting color. Additionally, on streets with "extra" capacity, the stormwater planting zone could be widened and extended into the generous traffic lane and/or a sidewalk. 


\section{COGITATIO}

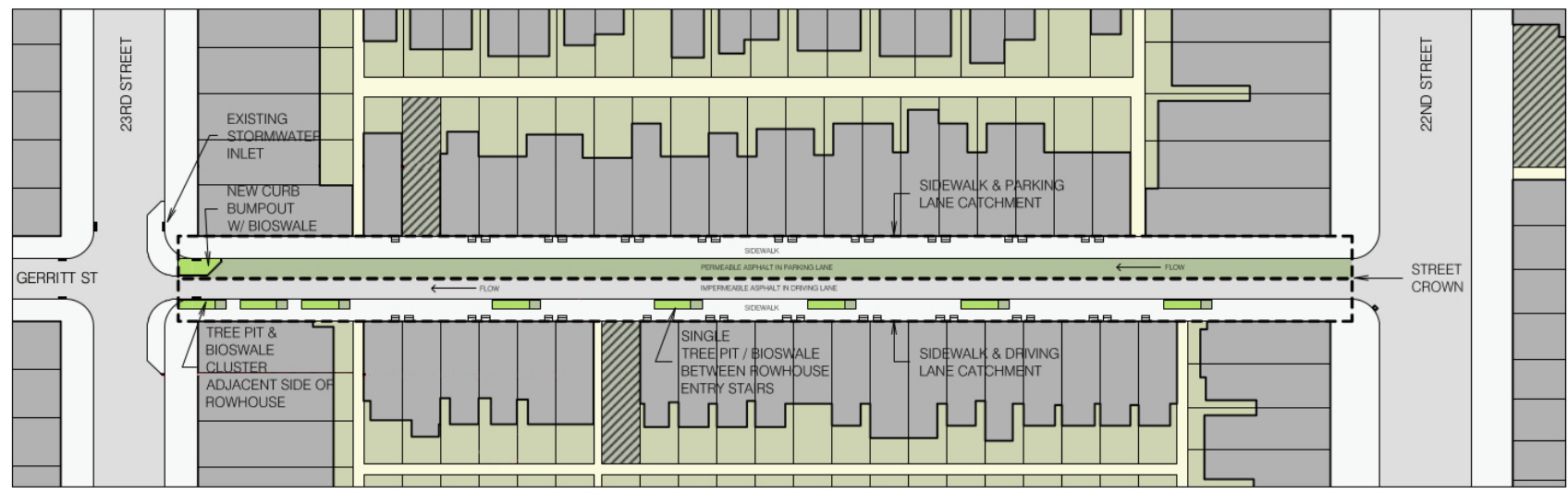

Figure 4. Model 1-Plan view of proposed streetscape GI.

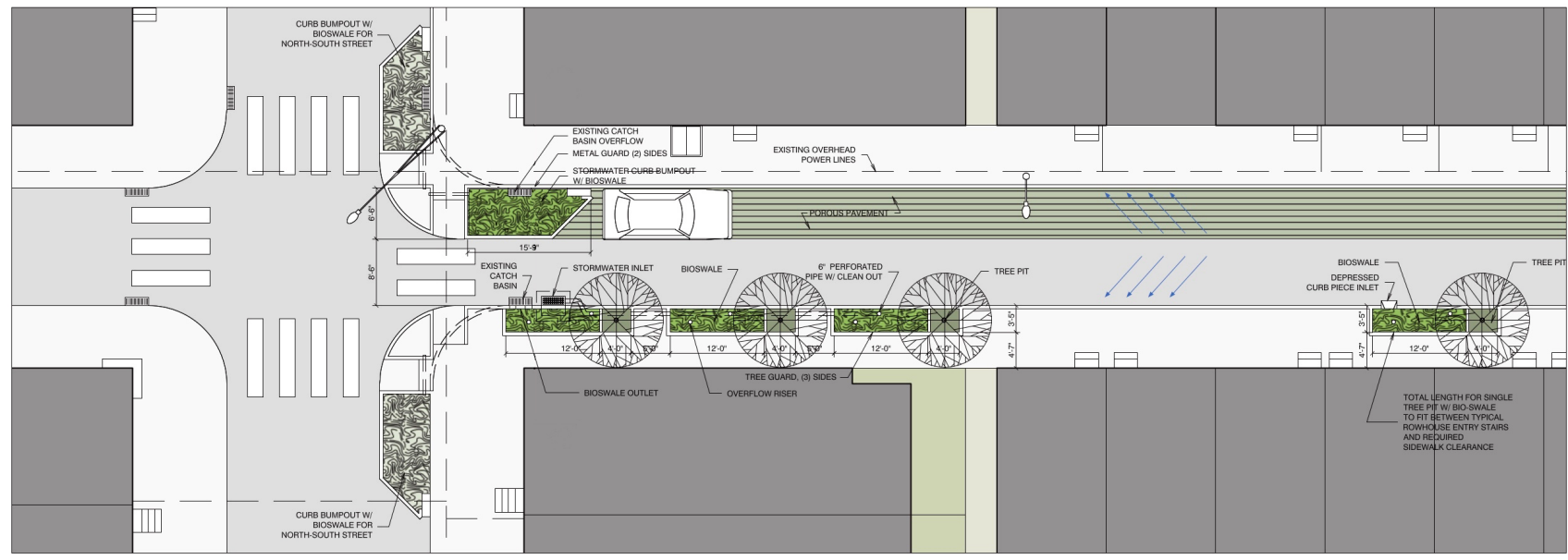

Figure 5. Model 1-Plan view of "gateway" arrangement of GI near the crosswalk and intersection.

\subsection{Model 2-Public vacant land alternative}

The physical analysis of land in Point Breeze revealed a number of publicly owned vacant parcels of land located at block corners (near stormwater inlets) on blocks with relatively high imperviousness fractions. In Model 2, we allow PWD to convert publicly-owned corner vacant parcels on blocks with at least $836 \mathrm{~m}^{2}$ of potential private contributing area to stormwater management facilities which, depending on local site conditions, could be rain gardens, infiltration/storage trenches, or stormwater basins (referred to in aggregate as rain gardens). Model 2 also includes all of the public right of way GI strategies, school, and park programs included in Model 1. During a given year, PWD chooses to allocate budget to developing vacant parcels prior to considering $\mathrm{GI}$ on streets. As in Model 1, private single-family residences may also elect to build green roofs or rain gardens, but receive no financial incentive from PWD to do so.

The designs for Model 2 (see Figures 6 and 7), combine public and private surface run-off for infiltration/storage on public property. A common block type in the neighborhood has a large open parcel and multiple smaller, relatively equal-sized residential parcels. In this design, stormwater is conveyed from the residential rooftops and rear yards via the modified internal alley to a rain garden and on to an infiltration/storage 'trench' beneath the large parcel, in this case a new basketball court. The infiltration/storage trench also, accommodates stormwater from the public parcel itself. With the addition of the some or all of the GI suggested in Model 2, it is possible to accommodate public street and sidewalk run-off and to consider sizing the infiltration/storage trench for additional public stormwater (from adjacent streets and sidewalks) and from crossstreet inner-alleys, as alley termination locations permit.

\subsection{Model 3-Private Vacant Land Alternative PLUS}

Because so much of the land area of Point Breeze is privately owned, Model 3 was developed in an attempt to characterize the potential of $\mathrm{Gl}$ on private property. This was initially accomplished by adding to the GI strategies of Model 2 four new dynamics in Model 3: the Raincheck program, Transportation Corridors program, Community-Assisted Maintenance program, and GI Banking and Credit program (BCP).

In Model 3, the Raincheck program subsidizes up to $80 \%$ of the costs associated with green roofs and rain gar- 


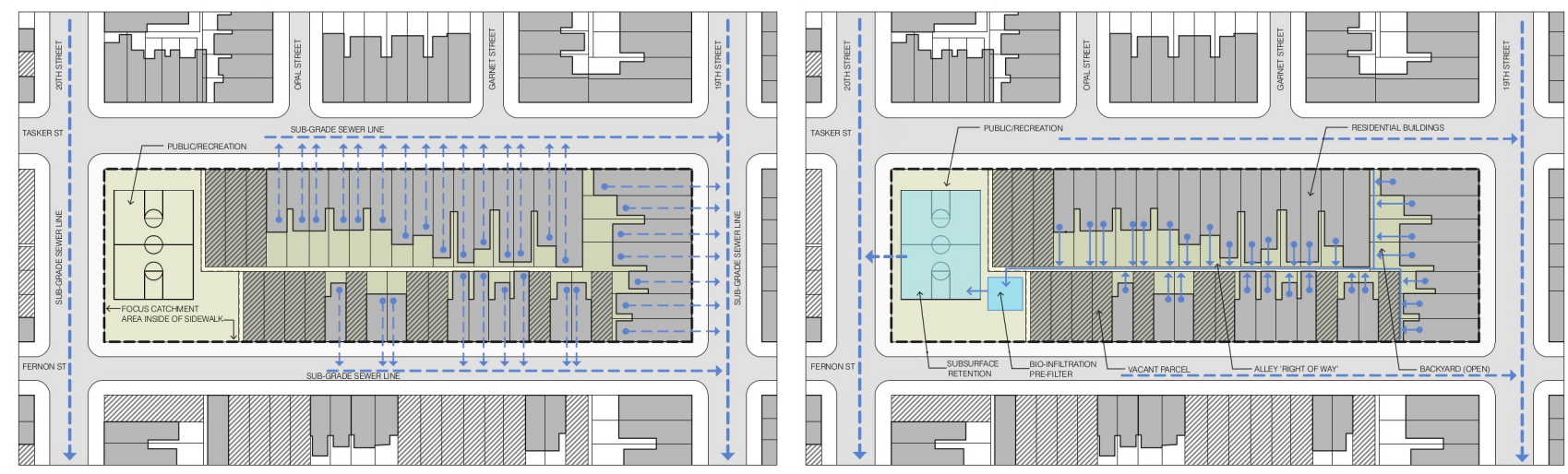

Figure 6. Model 2-Plan view of catchment area and existing drainage (left), and proposed GI (right).

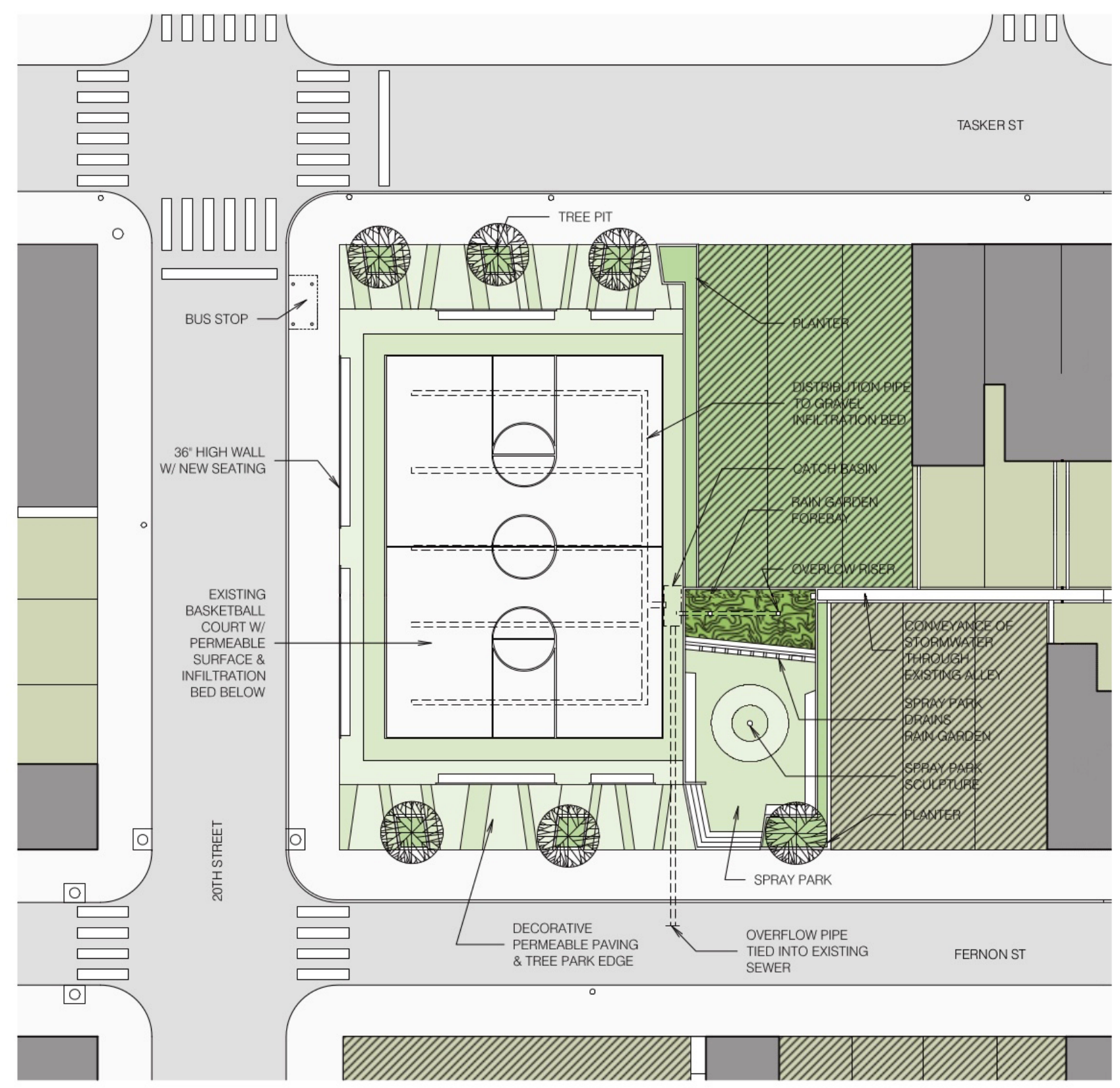

Figure 7. Model 2-Plan view of block-end parcel detail, including a central rain garden and permeable ball court. 
dens on private land. Note that this policy differs slightly from PWD's actual Raincheck program, developed after this research was completed. These differences are discussed below. Under the Transportation Corridors program, PWD preferentially installs public right-of-way GI near transportation corridors (e.g., bus stops) over other street locations. This has a significant impact on $\Gamma_{\text {hist }}$ since private property owners come into contact with these $\mathrm{Gl}$ installations more frequently than they do other GI installations in less heavily trafficked sections of the neighborhood. The Community-Assisted Maintenance Program assumes that PWD engages communitybased organizations to provide O\&M for $\mathrm{GI}$ on public lands (excluding $\mathrm{GI}$ on streets). If performed through the Community-Assisted Maintenance Program, O\&M costs are assumed to be a fraction (75\%) of market rate. Finally, the $\mathrm{BCP}$ allows privately owned vacant lots to be reconfigured for stormwater management, and credits to be sold throughout the city, not unlike the stormwater credit program in Washington D.C. (Department of Energy \& Environment [DOEE], 2013).

The design for Model 3 (see Figure 8) emphasizes the potential role of private vacant land, with a focus on utilizing single corner vacant parcels or on two adjacent parcels located near alley ends. Internal parcels may be designed in combinations of two or three, as building setbacks for GI typically take up useable area on single lots and a larger number of aggregated parcels may have higher value for construction purposes.

According to input from residents, the corner lots are seen as valued locations for small parks. Vacant corner parcel locations may also add significantly to the capacity of stormwater bump-outs and stormwater planters and by design, green intersections. Selected locations for higher-value corner lots may be aligned with transit corridors. One example of this concept is Point Breeze Avenue, a distinct diagonal and historically active commercial street, that could possibly benefit from spatially redefining the street into distinct and connected destination areas, focused on stormwater management 'parks' and taking advantage of the triangular parcels formed by remnant geometry.

A goal of this conceptual design is to envision a physical, social and economic network for stormwater management facilities that can be tied together at multiple scales in order to achieve PWD goals, and foster community revitalization and sustainable redevelopment.

After running Model 3 with all of these new dynamics and performing a sensitivity analysis, it was determined that incorporation of the Raincheck, Transportation Cor-

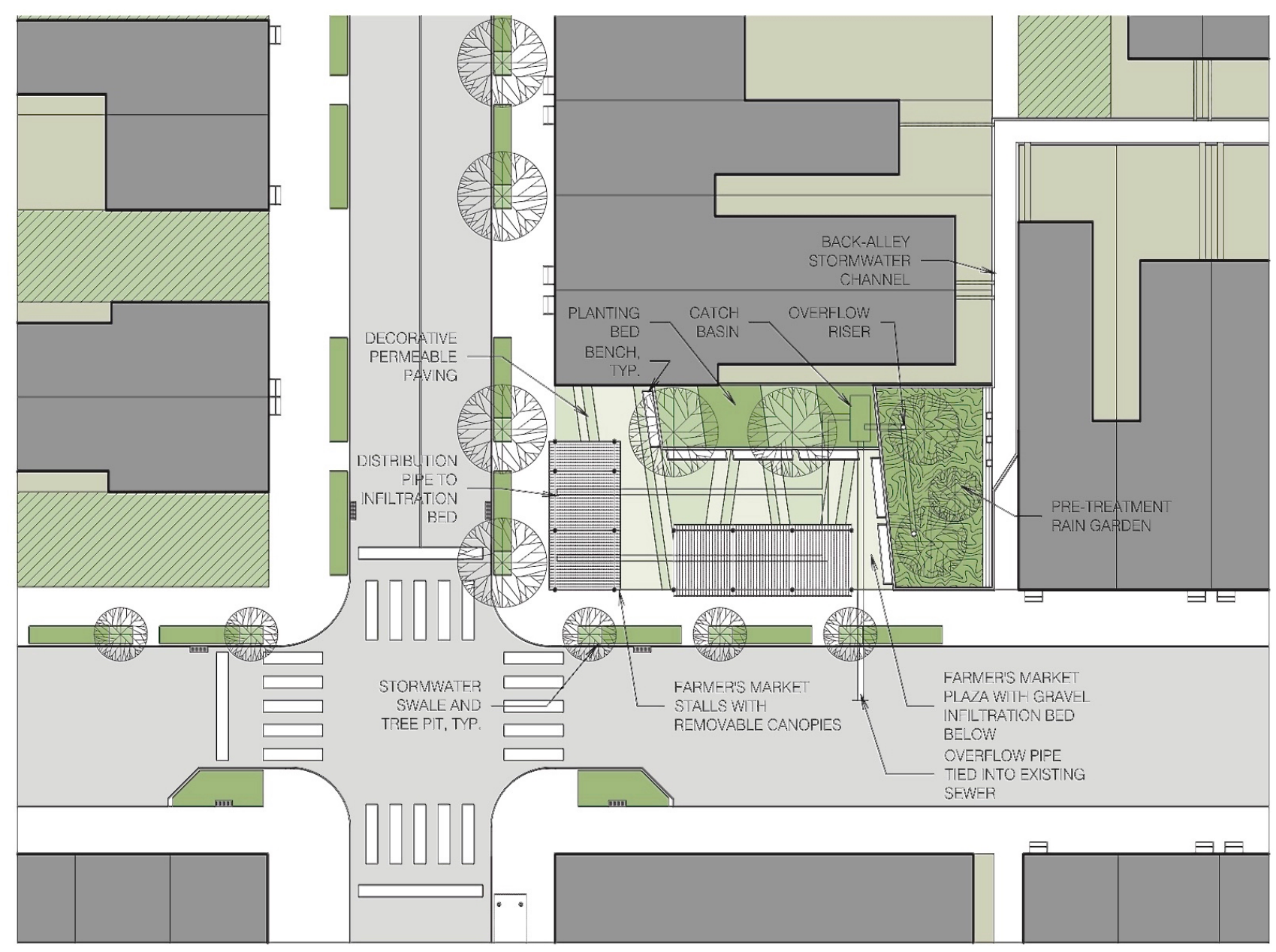

Figure 8. Model 3-Conceptual design for corner lot. 
ridors, and Community-Assisted Maintenance programs minimally changed the results beyond those obtained from Model 2. The most influential change was the BCP, which is described in greater detail below.

\subsubsection{The GI Banking and Credit Program (BCP)}

Approximately three quarters of the vacant parcels of land in Philadelphia are privately owned (Philadelphia Redevelopment Authority, 2010). If some means of encouraging the management of stormwater of GI on private land could be developed, the goal of merging vacant land revitalization efforts with stormwater management could be significantly advanced. In Model 3, we allow a third-party GI banker to purchase privately owned vacant land in Point Breeze, reconfigure it to manage stormwater runoff originating on other private parcels within the same census block, and then sell the credits to developers and property owners from anywhere in Philadelphia, as compensation for the stormwater runoff implications from either new developments, or existing commercial and institutional developments subject to PWD's impervious billing policy.

This strategy incentivizes stormwater management on private properties, an important stormwater "sector" that is not currently addressed in PWD's Implementation and Adaptive Management Plan. A BCP is a means by which PWD and the City of Philadelphia can leverage vacant lands for meeting stormwater management goals (and realizing other benefits) without acquiring these lands. Moreover, it would create a market for private lands committed to stormwater management. Different uses of vacant land present trade-offs for PWD, neighborhood residents, and developers. The trade-offs faced by each of the groups is outlined below in Table 5 .

A plot showing the expenses and income of a hypothetical BCP is presented in Figure 9. The bank begins with acquisition of vacant land at market prices and construction of stormwater management facilities. At present, vacant land is relatively inexpensive in parts of the Point Breeze neighborhood and it is assumed the PWD would be willing to contribute substantially to construction costs. PWD's willingness to contribute to a BCP is related to its need to utilize vacant land for stormwater management and its confidence in the success of a BCP as a sustainable partner for ongoing stormwater management in Point Breeze and beyond. Once the vacant land is developed for stormwater management, "credits" for stormwater management up to the capacity of the stormwater controls on the banked land are sold to commercial landowners, developers, and others with incentives or requirements for retaining/infiltrating stormwater. As depicted in Figure 4, the sale of stormwater credits must be sufficient to cover land acquisition, construction and O\&M costs minus the contribution that PWD or another interested organization makes toward costs and to generate revenue. Consistent with PWD's adaptive strategy for implementing GI over the 30-year program, it is assumed that PWD will be most willing to contribute to construction costs on GI bank lands at the

Table 5. Value of vacant land to different interest groups.

\begin{tabular}{lll}
\hline Interest group & Benefits of vacant land use for GI & Liabilities of vacant land use for GI \\
\hline PWD & $\begin{array}{l}\text { Use of vacant land may be necessary to meet } \\
\text { directly connected impervious areas targets }\end{array}$ & $\begin{array}{l}\text { May not want to become landowner of vacant land } \\
\text { as Gl reduces number of rate- paying customers }\end{array}$ \\
\hline Neighbors & $\begin{array}{l}\text { Gl on vacant land may provide environmental, } \\
\text { aesthetic and social benefits to neighbors }\end{array}$ & $\begin{array}{l}\text { Reduces opportunity for development the } \\
\text { community desires such as affordable housing }\end{array}$ \\
\hline Developers & $\begin{array}{l}\text { Opportunity to meet stormwater requirements } \\
\text { for new construction }\end{array}$ & Vacant land not available for development \\
\hline
\end{tabular}

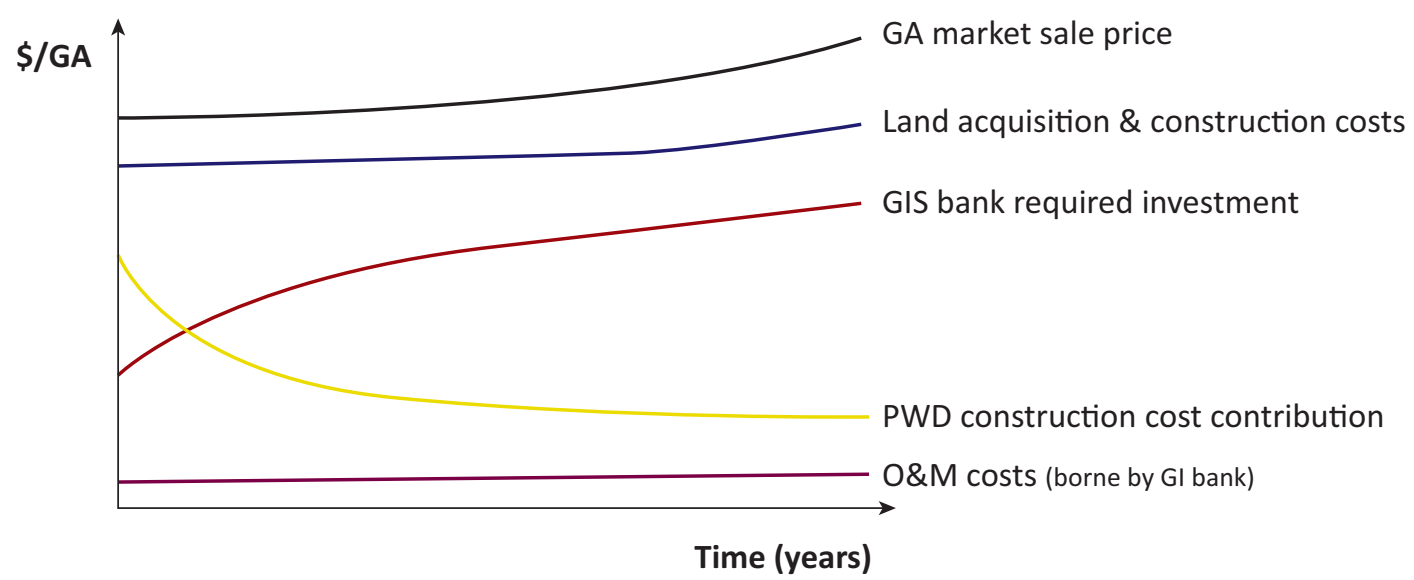

Figure 9. Economics of the BCP. 
model outset and will less willing over time, as the GI bank is expected to become a sustainable entity.

It is worth noting the following assumptions are made in simulating a BCP in the Point Breeze ABM. In Model 3, the BCP is assumed to have enough capital to purchase and develop 5 vacant lots at the project outset, PWD is willing to contribute $100 \%$ of GI construction costs, and there are always individuals willing to buy stormwater credits at the market rate (the bank has an infinite market). It is also assumed that, at the project outset, the $\mathrm{Gl}$ credit value is set equal to the land cost + construction cost + 30-year O\&M cost (including rate escalation) $+10 \%$ profit margin for the $\mathrm{Gl}$ bank, and the GI bank buys additional vacant land as soon as it has sufficient capital available.

\subsection{Modeling Results}

Figure 10 presents the time evolution of GA in Point Breeze as predicted by Models 1, 2, and 3. The grey areas in the charts represent the range of possible GA outcomes obtained in all 120 stochastic ensemble runs of the 30-year sequence. The median predicted GA values for each year are shown with a line.
Though models 1 and 2 arrive at a similar overall mean percent GA, there is more uncertainty in Model 2, and only Model 3 suggests the possibility that the $47 \%$ goal can be approached.

Figure 11 depicts the net new greened acres associated with each of the types of GI strategies that are implemented in the model. Streetscape GI will account for a large percentage of greened acres in all three models. However, in Model 3, the private vacant land strategy is likely to produce even more greened acres.

\section{Discussion}

Our modeling suggests that is unlikely that Philadelphia will meet their stormwater management goals unless PWD gets innovative regarding the management of stormwater originating on private land. As the GCCW program is currently structured (Model 1), it does not achieve the $47 \%$ goal at the neighborhood scale in Point Breeze. Model 2 represents only a marginal improvement in results over Model 1 simply because there are not many corner publicly owned vacant lots available in Point Breeze, relative to the total land area. A comparison of Model 1 and Model 2 also reveals greater vari-
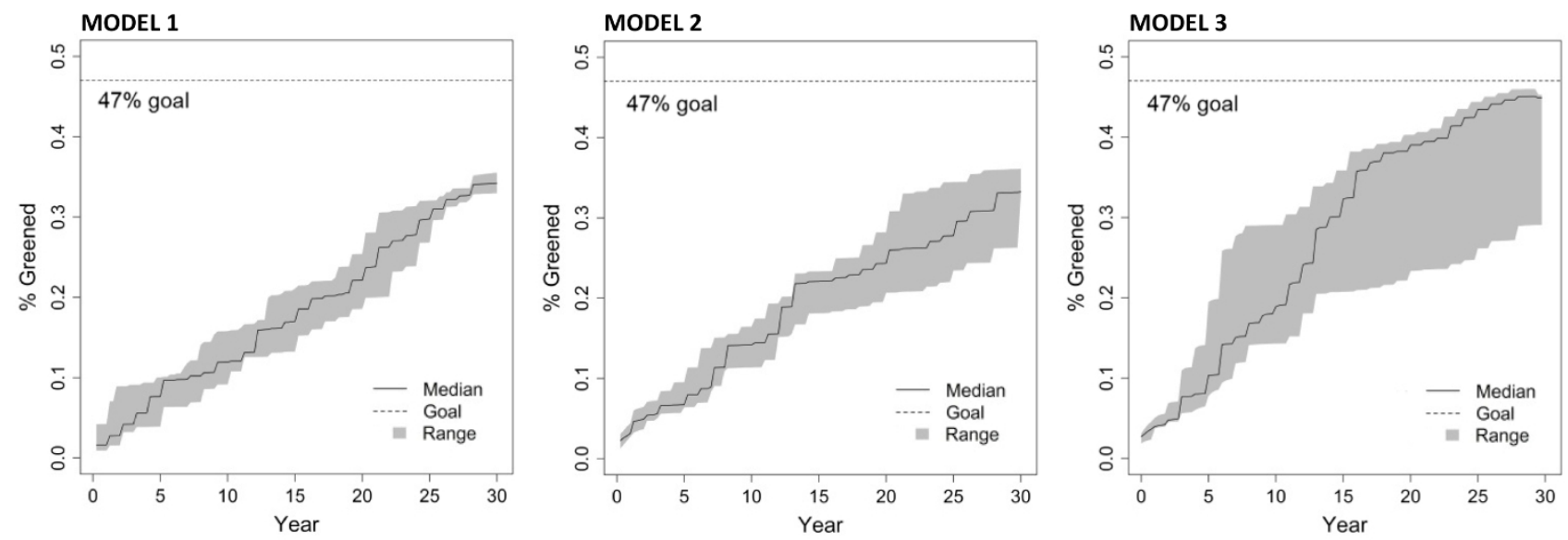

Figure 10. Results of model runs in terms of greened acres over time.
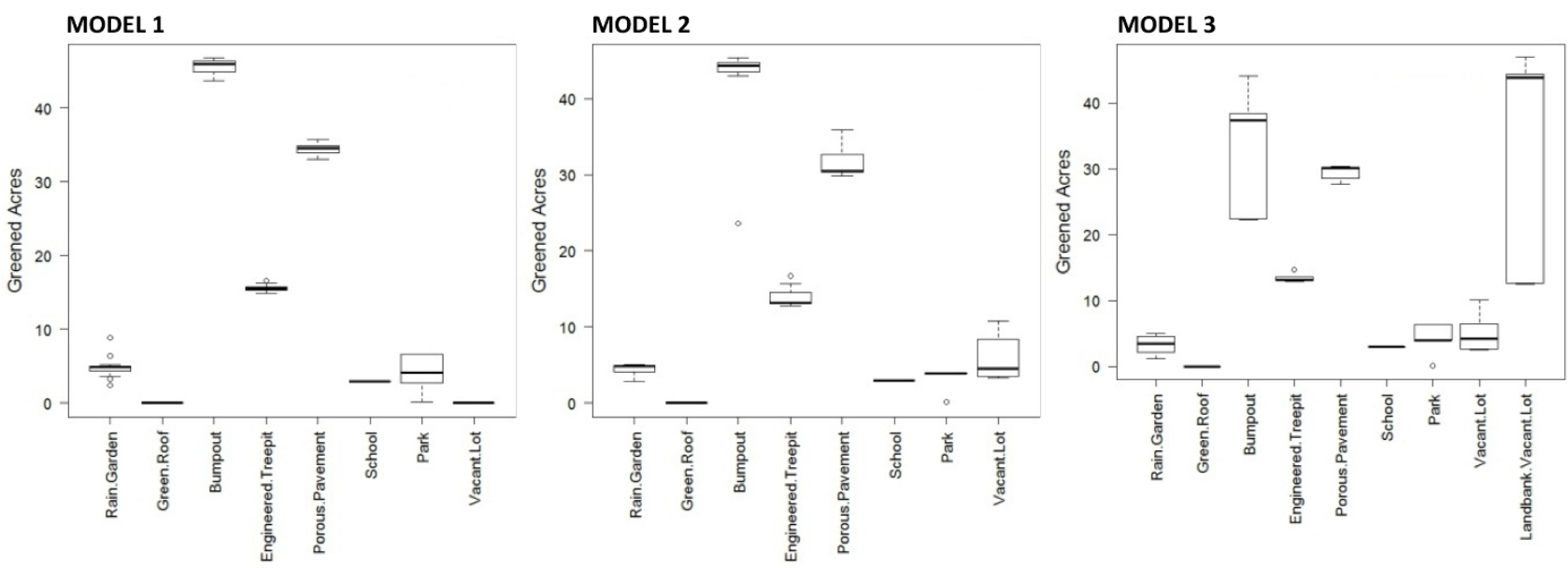

Figure 11. Results of model runs in terms of net greened acres after 30 years, by GI type. 
ability in the results of Model 2 after 30 years. This finding is attributed to the path dependency associated with early GI decisions. If these decisions tend to favor more cost-effective GI (e.g., involve corner vacant lots), there is more money available in the long term for Gl implementation and the number of GA generated is greater. If, on the other hand, early $\mathrm{GI}$ installations are less cost effective, less GA ultimately gets built. More options create more variability in the results.

Model 3 gets the closest to the $47 \%$ goal for Point Breeze, underscoring the importance of working with private landowners in helping PWD achieve its GI goals in this neighborhood. After 30 years, there is still great potential variability in the results (demonstrating the same path dependency described above), but the fact that the median net GA is near the upper end of range demonstrates that the GI bank played a key role in most of the model runs.

Streetscape Gl strategies (bump-outs, tree trenches, and permeable pavement) will account for a large percentage of GA in all three models. Because these results are contingent upon assumptions made about how PWD works with partners, PWD's evolving collaboration with the Streets Department is thus considered to be of high value.

Clearly, the private vacant land strategy in Model 3 has the potential to produce the most net GA. In fact, trends since the completion of this work indicate an expanding interest in tailoring policy to incentivize Gl installation on private land. Philadelphia has since launched several promising initiatives, including its Raincheck program, which directly offsets the cost of certain residential GI; the Greened Acre Retrofit Program, which provides funding to project aggregators who can build large-scale Gl across multiple properties; and the Stormwater Management Incentive Program, which provides grants for GI on non-residential private lands.

Although private rain gardens occur (especially in Models 1 and 2), they do not make up a large percentage of the new GA that will appear in Point Breeze. Though these initiatives carry great value by helping to engage the community, it may be useful for PWD to seek opportunities to engender greater community support for streetscape $\mathrm{GI}$, since these technologies will go much further towards achieving its stormwater management goals.

The ephemeral effect of neighborhood organizations is noticeable, but disappears by the end of the simulation. These issues are not reported here, but are the subject of a separate paper (Montalto et al., 2012).

\section{Conclusions}

This study investigated three ways that PWD could implement $\mathrm{Gl}$ in Point Breeze, in an effort to achieve its goal of $47 \% \mathrm{Gl}$ coverage at the neighborhood scale. We note that, to our knowledge, the city's legal obligations do not specify any requirement regarding the spatial den- sity of GI across the city, meaning that if GI were concentrated at higher densities in some neighborhoods, lower densities would likely be allowable in other areas, as long as the $47 \%$ goal is achieved citywide. This said, the modeling effort suggests that programs that incentivize $\mathrm{GI}$ on vacant private land represent a potentially significant regulatory compliance strategy for residential neighborhoods like Point Breeze. Specifically, the proposed GI banking mechanism would allow stormwater management on private land to be marketed city wide, significantly advancing $\mathrm{Gl}$ penetration beyond the level feasible using only publicly-owned land, including in the right of way.

Comparable market-based regulatory strategies have been proposed or are in operation as a means of improving air quality (Napolitano et al., 2007), climate change (Ellerman \& Buchner, 2007; Freeman \& Kolstad, 2006), water quality (Hamstead \& BenDor, 2010; Lal et al., 2009; Mariola, 2012), impervious surfaces (Welty et al., 2005), fisheries (Annala, 1996), and wetlands (NRC, 2001). In 2008, the U.S. Department of Agriculture established an Office of Environmental Markets for carbon sequestration, water quality, wetlands, biodiversity, and other ecosystem services.

This research suggests that a similarly structured approach for trading GI credits could help Philadelphia comply with water quality regulations, and the same conclusion appears to be emerging in other locales. For example, in 2013, Washington D.C.'s Department of Energy and the Environment created a Stormwater Retention Credit program to support compliance with new stormwater rules. Property owners may offset up to $50 \%$ of their onsite retention requirement by generating Stormwater Retention Credits either by installing GI on self-owned offsite properties, or by purchasing credits that are generated on properties that exceed their own regulatory requirements or voluntarily installing GI. This program is expected to achieve higher retention volumes throughout the district, and could result in a greater number of smaller GI investments going after the low-hanging fruit of "first flush" stormwater, containing the most concentrated pollutants. Moreover, the off-site provision in this regulation has the potential to prioritize GI investments in less affluent areas (DOEE, 2013).

DC's program is not unlike the program assumed in Model 3, but the final design of this kind of program for Philadelphia would obviously require further study of the values and motivations of the city's residents and property owners. Critical information for policy makers who are designing financial instruments for use of private property owners include the public's willingness to implement GI on private properties (Baptiste, Foley, \& Smardon, 2015) as well as both the physical and financial barriers to program delivery (Ando \& Freitas, 2011). The engagement reported on in Travaline et al. (2015) is a start, but additional work would elicit input from a larger sampling of the owners of vacant land across the city, accompanied by physical surveying of their location 
and the level of effort that would be involved to divert nearby runoff to them.

A final conclusion of this work is the need to act soon to foster a diverse portfolio of $\mathrm{Gl}$ implementation pathways. Because of the strict timetables associated with many stormwater regulations, water utilities like PWD need to achieve compliance within specific periods of time. A GI plan that replaces regular roofs with green roofs only at the end of their useful life, or that includes a Streets Department pledge to install porous pavement only as part of its ongoing urban repaving efforts will likely "miss the mark". If water utilities are to include GI as an integral part of their infrastructure strategies, they will need some assurance that threshold levels of implementation will be achieved within rigidly defined time frames. This may be approached by continuing to refine how to operationalize sustainability planning concepts to inform this newest investment in the quality and texture of our cities.

\section{Acknowledgments}

This work was financed in part by a grant from the Community Conservation Partnerships Program, Keystone Recreation, Park and Conservation Fund, under the administration of the Pennsylvania Department of Conservation and Natural Resources, Bureau of Recreation and Conservation (BRC-TAG-13.3-220). Additional funds were provided by the Philadelphia Water Department.

\section{Conflict of Interests}

The authors declare no conflict of interests.

\section{References}

Ando, A. W., \& Freitas, L. P. (2011). Consumer demand for green stormwater management technology in an urban setting: The case of Chicago rain barrels. Water Resources Research, 47(12). doi:10.1029/ 2011WR011070

Annala, J. H. (1996). New Zealand's ITQ system: Have the first eight years been a success or a failure? Reviews in Fish Biology and Fisheries, 6(1), 43-62. doi:10.1007/BF00058519

Bah, A., Touré, I., Le Page, C., Ickowicz, A., \& Diop, A. T. (2006). An agent-based model to understand the multiple uses of land and resources around drillings in Sahel. Mathematical and Computer Modelling, 44(5), 513-534.

Baptiste, A. K., Foley, C., \& Smardon, R. (2015). Understanding urban neighborhood differences in willingness to implement green infrastructure measures: A case study of Syracuse, NY. Landscape and Urban Planning, 136, 1-12. doi:10.1016/ j.landurbplan.2014.11.012

Barthel, R., Rojanschi, V., Wolf, J., \& Braun, J. (2005). Large-scale water resources management within the framework of GLOWA-Danube. Part A: The groundwater model. Physics and Chemistry of the Earth, Parts $A / B / C, 30(6), 372-382$. doi:10.1016/ j.pce.2005.06.003

Berger, T., Birner, R., McCarthy, N., Díaz, J., \& Wittmer, H. (2007). Capturing the complexity of water uses and water users within a multi-agent framework. Water Resources Management, 21(1), 129-148.

Conrad, F. (2009). Point Breeze Avenue revitalization project recommendations. Philadelphia, PA: Point Breeze Avenue Business Association Inc.

Davis, D. N. (2000). Agent-based decision-support framework for water supply infrastructure rehabilitation and development. Computers, Environment and Urban Systems, 24(3), 173-190. doi:10.1016/S01989715(99)00056-3

Department of Energy \& Environment. (2013). Stormwater retention credit trading program. Washington, DC: DOEE. Retrieved from https://doee.dc.gov/src

Ellerman, A. D., \& Buchner, B. K. (2007). The European Union emissions trading scheme: Origins, allocation, and early results. Review of Environmental Economics and Policy, 1(1), 66-87. doi:10.1093/ reep/rem003

Fagiolo, G., Moneta, A., \& Windrum, P. (2007). A critical guide to empirical validation of agent-based models in economics: Methodologies, procedures, and open problems. Computational Economics, 30(3), 195-226. doi:10.1007/s10614-007-9104-4

Freeman, J., \& Kolstad, C. D. (2006). Moving to markets in environmental regulation: Lessons from twenty years of experience. Oxford University Press.

Grimm, V., Berger, U., DeAngelis, D. L., Polhill, J. G., Giske, J., \& Railsback, S. F. (2010). The ODD protocol: A review and first update. Ecological Modelling, 221(23), 2760-2768. doi:10.1016/j.ecolmodel.2010.08.019

Hamstead, Z. A., \& BenDor, T. K. (2010). Overcompliance in water quality trading programs: Findings from a qualitative case study in North Carolina. Environment and Planning C: Government and Policy, 28(1), 1-17. doi:10.1068/c0887j

Jager, W., \& Mosler, H. J. (2007). Simulating human behavior for understanding and managing environmental resource use. Journal of Social Issues, 63(1), 97-116. doi:10.1111/j.1540-4560.2007.00498.x

Lal, H., Delgado, J. A., Gross, C. M., Hesketh, E., McKinney, S. P., Cover, H., \& Shaffer, M. (2009). Marketbased approaches and tools for improving water and air quality. Environmental Science \& Policy, 12(7), 1028-1039.

Mariola, M. J. (2012). Farmers, trust, and the market solution to water pollution: The role of social embeddedness in water quality trading. Journal of Rural Studies, 28(4), 577-589. doi:10.1016/j.jrurstud.2012.09.007

Montalto, F., Behr, C., Alfredo, K., Wolf, M., Arye, M., \& Walsh, M. (2007). Rapid assessment of the cost-effectiveness of low impact development for CSO control. Landscape and Urban Planning, 82(3), 
117-131. doi:10.1016/j.landurbplan.2007.02.004

Montalto, F. A., Bartrand, T. A., Waldman, A. M., Travaline, K. A., Loomis, C. H., McAfee, C., . . . Boles, L. M. (2013). Decentralised green infrastructure: The importance of stakeholder behaviour in determining spatial and temporal outcomes. Structure and Infrastructure Engineering, 9(12), 1187-1205. doi:10.1080/15732479.2012.671834

Moss, S., \& Norling, E. (2005). Multi-agent-based simulation: Why bother? In International Workshop on Multi-Agent Systems and Agent-Based Simulation (pp. 1-13). Berlin: Springer. doi:10.1007/ 11734680_1

Napolitano, S., Schreifels, J., Stevens, G., Witt, M., LaCount, M., Forte, R., \& Smith, K. (2007). The US acid rain program: Key insights from the design, operation, and assessment of a cap-and-trade program. The Electricity Journal, 20(7), 47-58. doi:10.1016/ j.tej.2007.07.001

National Research Council. (2001). Compensating for wetland losses under the Clean Water Act. Washington, DC: National Academy Press.

Philadelphia Redevelopment Authority. (2010). Vacant land management in Philadelphia: The costs of the current system and the benefits of reform. Retrieved from http://www.econsult.com/projectreports/Va cantLandFullReportForWeb.pdf

Philadelphia Research Initiative. (2016). Philadelphia's changing neighborhoods: Gentrification and other shifts since 2000. Philadelphia, PA: The Pew Charitable Trusts. Retrieved from http://www.pewtrusts. org/en/research-and-analysis/reports/2016/05/phil adelphias-changing-neighborhoods

Philadelphia Water Department. (2014). Stormwater management guidance manual (Version 2.1). Philadelphia, PA: PWD. Retrieved from https://www. pwdplanreview.org/upload/pdf/Full\%20Manual\%20 (Manual\%20Version\%202.1).pdf

Romero, M. (2017). How Philly's poverty rate has changed since 1970, by district. Curbed Philadelphia. Retrieved from https://philly.curbed.com/2017/1/ 30/14439888/philadelphia-poverty-rate-by-neighbor hood

Smajgl, A., Brown, D. G., Valbuena, D., \& Huigen, M. G. (2011). Empirical characterisation of agent behaviours in socio-ecological systems. Environmental Modelling \& Software, 26(7), 837-844. doi:10.1016/ j.envsoft.2011.02.011

Tillman, D. E., Larsen, T. A., Pahl-Wostl, C., \& Gujer, W. (2005). Simulating development strategies for water supply systems. Journal of Hydroinformatics, $7(1)$, 41-51.

Travaline, K., Montalto, F., \& Hunold, C. (2015). Deliberative policy analysis and policy-making in urban stormwater management. Journal of Environmental Policy \& Planning, 17(5), 691-708. doi:10.1080/ 1523908X.2015.1026593

Valderrama, A., \& Davis, P. (2015). Wanted: Green acres. How Philadelphia's Greened Acre Retrofit Program is catalyzing low-cost green infrastructure retrofits on private property. (Issue Brief 14-12-b). New York: Natural Resources Defense Council. Retrieved from https://www.nrdc.org/resources/wanted-green-acres -how-philadelphias-greened-acre-retrofit-programcatalyzing-low-cost

Voinov, A., \& Bousquet, F. (2010). Modelling with stakeholders. Environmental Modelling \& Software, 25(11), 1268-1281. doi:10.1016/j.envsoft. 2010.03.007

Welty, C., Fraley, L., Hanlon, B., Hanson, R., Kolb, N., McGuire, M. P., . . . Vicino, T. J. (2005). Final report: Using an impervious permit allowance system to reduce impervious surface coverage for environmental sustainability. Baltimore, MD: University of Maryland-Baltimore County. Retrieved from http://cfpub.epa.gov/ncer_abstracts/index.cfm/fuse action/display.abstractDetail/abstract/7148/report/F

Zhou, Q. (2014). A review of sustainable urban drainage systems considering the climate change and urbanization impacts. Water, 6(4), 976-992. doi:10.3390/w6040976

\section{About the Authors}
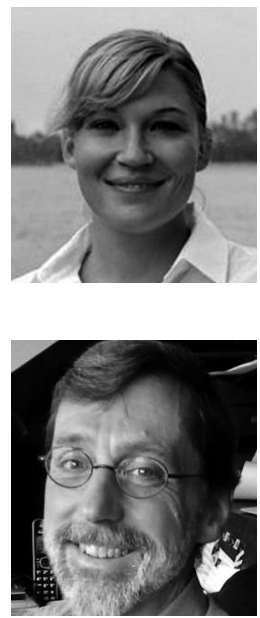

Kate Zidar is an Environmental Planner with a focus on coastal resilience and communications. Kate was a founding member of the Stormwater Infrastructure Matters (S.W.I.M.) Coalition, a policy think tank that figured centrally in establishing Green Infrastructure as a mainstream practice in New York City. She founded the North Brooklyn Compost Project, a community-scale compost operation that preceded citywide collection of organic waste in NYC. Kate taught for a decade at her alma mater Pratt Institute Graduate Center for Planning and the Environment. She currently works as a consultant throughout the US East Coast, Caribbean and Central America.

Tim Bartrand is a research engineer with the Environmental Science, Policy and Research Institute (ESPRI) and with Corona Environmental Consulting, LLC. He specializes in drinking water disinfection, statistical analysis of water quality data, risk analysis and water quality in building water systems. He holds a PhD from Drexel University and has nearly 20 years of experience as an environmental engineer. 


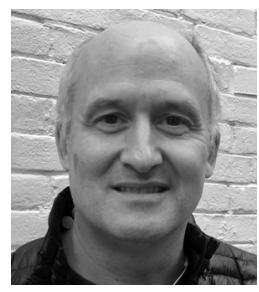

Charles Loomis is a principal at Charles Loomis Chariss McAfee Architects, with over 25 years of experience in the design and construction of a wide range of projects. Firm work includes multi-story housing, green infrastructure studies for the Philadelphia Water Department, land planning for the Philadelphia Industrial Development Corporation, new building design and landscape integration for the Fairmount Park Conservancy, institutional renovations for local schools, single family residences, furnishings, and product design. Charles is a founder and council member of the Greater Philadelphia Passive House Association, has taught Building Technology courses at Philadelphia University, is a LEED AP, and Certified Passive House Consultant and Tradesperson. He received a Masters of Architecture from Yale University.

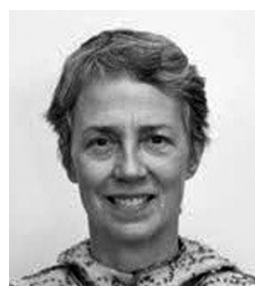

Chariss McAfee is a principal at Charles Loomis Chariss McAfee Architects, with over 25 years of experience in the design and construction of a wide range of projects. The work of their firm centers on the understanding and transformation of place, material exploration, and sustainable design. Chariss has taught Design and Technology courses and remains an active architectural studio critic in Philadelphia's universities. She received a Masters of Architecture from Yale University.

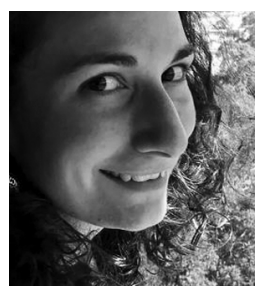

Juliet Geldi is a Project Architect at KSS Architects. She holds a Masters of Architecture from University of Pennsylvania and a Bachelors of Science in Engineering, Civil Engineering Systems, University of Pennsylvania, where she graduated magna cum laude. She received the E. Lewis Dales Traveling Fellowship and was part of the Grand Prize winning team for the Van Alen Institute's "Urban Voids" Competition. With a diverse design background that includes museum and exhibit design, stormwater management planning, and time spent as a principal of a small firm focused on high-end residential projects, she holds the modernist belief that beauty can enhance people's lives, and that the beauty that comes from a well-designed building should be accessible to all people.

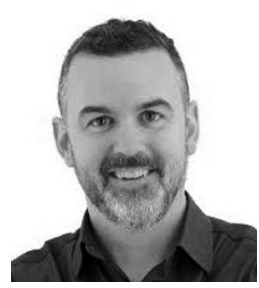

Gavin Riggall is a practicing architect and designer at JacobsWyper Architects in Philadelphia, Pennsylvania. He has extensive experience with higher education, cultural, and institutional building types. Since graduating from the University of Pennsylvania, he has taught both architectural visualization and interdisciplinary architecture/landscape architecture design studios within PennDesign's graduate program. Most recently, he taught alongside architect Tony Atkin and landscape architect Laurie Olin in design studios focused on exploring culturally acceptable modes of sustainable planning and building practices in Pueblo and Navajo communities of northern New Mexico. He also continues to research and explore how green infrastructure can be introduced into urban landscapes and buildings.

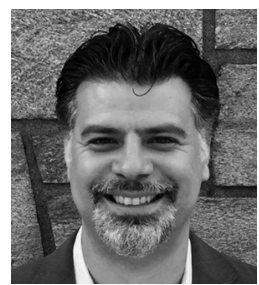

Franco Montalto is a civil engineer with a strong background in both applied and theoretical approaches to solving complex environmental problems. He has a particular interest in the development of ecologically, economically, and socially sensible solutions to urban environmental problems, with a focus on sustainable water resources engineering. He joined Drexel in September 2007 after a twoyear research fellowship at The Earth Institute at Columbia University, and adjunct teaching at The Cooper Union for the Advancement of Science and Art in New York City. He also serves as the Director of the North American Hub of the Urban Climate Change Research Network (UCCRN) and is Founder and President of eDesign Dynamics LLC, an environmental consulting firm also based in New York City. 